\title{
The New Demographic Transition: Most Gains in Life Expectancy Now Realized Late in Life
}

\author{
Karen N. Eggleston and \\ Director of the Stanford Asia Health Policy Program and Center Fellow at the Shorenstein Asia- \\ Pacific Research Center \\ Victor R. Fuchs \\ Henry J. Kaiser, Jr., Professor Emeritus in the Departments of Economics and of Health \\ Research and Policy, and Senior Fellow, Stanford Institute of Economic Policy and Research, \\ both at Stanford University, Stanford, California
}

\section{Abstract}

The share of increases in life expectancy realized after age 65 was only about 20 percent at the beginning of the $20^{\text {th }}$ century for the US and 16 other countries at comparable stages of development; but that share was close to 80 percent by the dawn of the $21^{\text {st }}$ century, and is almost certainly approaching 100 percent asymptotically. This new demographic transition portends a diminished survival effect on working life. For high-income countries at the forefront of the longevity transition, expected lifetime labor force participation as a percent of life expectancy is declining. Innovative policies are needed if societies wish to preserve a positive relationship running from increasing longevity to greater prosperity.

The original "demographic transition" describes a process that began in Europe by the early 1800 s with decreases in mortality followed, usually after a lag, by decreases in fertility (Davis 1945; for an overview in this journal, see Lee 2003). According to Lee and Reher (2011, p.1), "this historical process ranks as one of the most important changes affecting human society in the past half millennium." The increase in life expectancy associated with this demographic transition has been accompanied by rising levels of per capita output, which have in turn spurred further improvements in population health through better nutrition and living standards (Fogel 1994; Barker 1990) and, especially since World War II, through advances in medical care (in this journal, Cutler, Deaton, and Lleras-Muney 2006). At the same time, increases in life expectancy have resulted in a higher proportion of each cohort living long enough to participate in the production of goods and services. Reductions in fertility are also closely linked to higher labor force participation rates among women (Galor and Weil 1996; Costa 2000; Guinnane 2011).

During the original demographic transition, mortality decline prior to fertility decline often led to larger cohorts concentrated in working ages; this transitional change in the age structure of the population provided a boost to income that has been called a "demographic 
dividend" (Bloom, Canning, and Sevilla, 2003). Swift (2011) documents a significant twoway positive relationship between life expectancy and GDP per capita between 1820 and 2001 for 13 high-income countries.

Now, the United States and many other countries are experiencing a new kind of demographic transition. Instead of additional years of life being realized early in the lifecycle, they are now being realized late in life. At the beginning of the twentieth century, in the United States and other countries at comparable stages of development, most of the additional years of life were realized in youth and working ages; and less than 20 percent was realized after age 65 . Now, more than 75 percent of the gains in life expectancy are realized after 65-and that share is approaching 100 percent asymptotically. The choice of age 65 to illustrate this new demographic transition is somewhat arbitrary, but if we used 60 or 70 instead, the results would be qualitatively similar.

The new demographic transition is a longevity transition: how will individuals and societies respond to mortality decline when almost all of the decline will occur late in life? This issue is broader and more far-reaching than the issue of cohort size in each age group, with its focus on the prospective retirement of the unusually large "baby boomer" cohort, and has important socio-economic implications independent of patterns of fertility.

When the gains in life expectancy occur mainly towards the end of life, they contribute more to the age bracket that is traditionally mostly retired rather than to the age bracket in prime working years. Retirees are highly dependent on transfers from the working population for living expenses, including large consumption of medical care. Thus, gains in life expectancy concentrated at the end of life can unsettle an economy's balance between production and consumption in ways that pose a long-run challenge for public policy. The obvious changes that are needed (at least "obvious" to many economists") would be to raise productivity, to raise the savings rate, and to raise the age of retirement, but how to accomplish such goals is controversial and uncertain.

This paper covers the years 1900-2007 for the United States and 16 other "developed countries," chosen for the continuity of their mortality data: Australia, Belgium, Canada, Denmark, England and Wales, Finland, France, Iceland, Italy, Netherlands, Northern Ireland, Norway, Scotland, Spain, Sweden, and Switzerland. We focus on demographic statistics including life expectancy at birth and at age 65, the percent of each birth cohort expected to survive to age 65 , and the share of the increase in life expectancy at birth realized after age 65. For the U.S. economy, we also calculate expected labor force participation for each birth cohort, which allows us to investigate how changes in mortality affect labor force participation and worklife as a share of life expectancy.

Results on the longevity transition and expected labor force participation for the United States and other high-income countries are followed by consideration of economic and social changes in China and other countries that are experiencing an earlier stage of the original demographic transition. The paper concludes with a brief discussion of the long-run implications of the new demographic transition. 


\section{The Longevity Transition}

To examine long-term trends in life expectancy at birth, we draw upon the life table in the Human Mortality Database, which offers high quality demographic data for selected countries and regions compiled by a respected group of demographers at <http:// www.mortality.org. We first extract data on life expectancy at birth; in particular, we calculate "period" life expectancy, which is the projected average age of death for a cohort if it experienced the age-specific death rates prevailing at the year of birth. We also look at rates of survival from birth to age 65 , and life expectancy at age 65 . We use the five-year period life tables since 1900 (or earliest available year) for each of the 17 countries or regions in the Human Mortality Database that have data extending back at least 70 years. The five-year intervals help to smooth annual fluctuations in demographic trends.

We calculate changes for nine overlapping 20-year intervals: 1907-1927, 1917-1937, and so on up to 1987-2007. ${ }^{1}$ (The years ending in "7" are chosen to represent mid-points of each of our five-year intervals.) To calculate the change in years lived past 65 , we first multiply survival to 65 by life expectancy at age 65 for each five-year period, and then take differences across 20-year intervals. Finally, we calculate the change in years lived past 65 as a percentage of change in life expectancy at birth for each country for each of the nine 20year intervals.

Figure 1A shows that life expectancy at birth has increased almost continuously for well over a century in high-income countries. Figure 1B illustrates that much of this rise in life expectancy was due to a particularly large fall in death rates for infants, children, and young adults, resulting in a sharp rise in the percentage of a cohort surviving to age 65. Survival rates from birth to age 65 more than doubled over the twentieth century from 40.9 percent in 1900-04 to 83.3 percent in 2005-09 in the United States. Similarly, survival rates from birth to age 65 in 16 high-income comparators increased from 42.0 to 87.8 percent over the same period.

The other major demographic change that contributes to the longevity transition is an increase in life expectancy at age 65, an increase which has become larger in recent decades as shown in Figure 2A. The interaction between the increase in life expectancy at age 65 and the increase in the percentage of the cohort that survives to age 65 has resulted in an exceptionally large increase in the share of the gain in life expectancy that is realized after age 65. As can be seen in Figure 2B, that share was only about 20 percent during each 20year period at the beginning of the twentieth century, but it was 76 percent in the United States and 78 percent for the 16-country mean by the end of the century, and is approaching

\footnotetext{
${ }^{1}$ For our detailed underlying data on the five-year averages for each country, see the on-line appendix with this paper at <http://ejep.org>. Appendix tables 1-3 show the decreases in the coefficient of variation across the 17 high income countries for the demographic variables portrayed in Figures 1 and 2. To include data for the United States prior to 1933 (when the Human Mortality Database series begins for the United States), we use life table data from U.S. National Vital Statistics Reports, derived from death registration states for the period 1900 to 1928, and for the whole United States thereafter (all races combined). For a small share of observations at the beginning of the century -- Australia, Canada, UK Northern Ireland in 1900-19; Spain in 1900; and the United States in 1905, 1915, and 1925 -- we use imputed values from regressions with year and country fixed effects and country-specific linear time trends.
} 
100 percent asymptotically. Our results here are quite similar to, and extend over time, those of Lee and Tuljapurkar (1997) based on the 1995 survival profile of the United States.

We can illustrate the shift in survival improvement toward older ages by comparing the age distribution of mortality decline between the first half and second half of the twentieth century for a region with particularly reliable long-run data, such as England and Wales. Figure 3 shows that between 1900-04 and 1950-54, declines in death rates were largest for infants and children, whereas between 1950-54 and 2000-04, declines were most salient for those over age 70. (In the on-line Appendix, Figure 1 shows that this pattern of age-specific mortality decline across the twentieth century was similar for Sweden. Figure 3 shows a slight increase in death rates for the oldest [90+] age groups between 1900-04 and 1950-54, perhaps because of small numbers, less reliable data, and/or survival of a less healthy cohort to those ages.)

The actual survival of a given birth cohort will differ from the estimates of life expectancy at birth when survival is changing over time. Remember, estimates of life expectancy at birth (what we earlier called "period" life expectancy) are based on the age-specific death rates prevailing at that year of birth. For example, in 1900-04, life expectancy at birth in England and Wales was 48.6 years. In contrast, the cohort born in 1900-04 had a cohort life expectancy (actual mean age of death) of 53.8 years, since they experienced part of the increase in survival shown in Figures 1-Figure 3. The cohort born only 17 years later experienced a cohort life expectancy of 62.4 years, whereas "period" life expectancy at birth did not reach that level until 1935-1939. ${ }^{2}$

Nevertheless, we find that estimates based on cohort life tables prepared by the Social Security Administration (Bell and Miller 2005) exhibit a similar trend towards survival gains realized late in life: for men, the share of life expectancy increases realized after age 65 was 28 percent between the 1900 and 1920 birth cohorts, rising to a projected 62 percent between the 1980 and 2000 birth cohorts. For women, the share of life expectancy gains realized after age 65 increased from 30 percent (between the 1900 and 1920 birth cohorts) to an estimated 69 percent (between the 1980 and 2000 birth cohorts).

The century-long demographic trends shown in Figure 1 and 2 have been similar in all 17 countries with available data. From a U.S. perspective, the main difference is lagging survival to 65 compared to the other 16 countries (the U.S. line is below the 16-country average in Figure 1B); also, the United States experienced a larger rise in female life expectancy at age 65 between the 1940s and 1970s than the other countries. The relative differences among countries have decreased over time, especially for life expectancy at birth and survival to age 65 .

\footnotetext{
${ }^{2}$ Survival gains have been so dramatic that period and cohort survival significantly differs. For example, age-specific death rates for England and Wales in 1900-04 would have led to only 43.7 percent of women and 36.4 percent of men surviving to 65 . But of the cohort born in 1900-04, 61.3 percent of women and 49.6 percent of men actually survived to age 65 .
} 


\section{The Longevity Transition and Expected Labor Force Participation}

One of the most significant economic effects of the longevity transition is on expected lifetime labor force participation, partly in terms of total years in the workforce and especially in terms of years in the workforce as a fraction of expected years of life. Two factors affecting the connection from life expectancy to years of work are whether the growing numbers of elderly are healthy enough to work, and the economic, social, and political pressures for a period of retirement at the end of life.

Greater longevity can have opposing effects on age-specific health status. If improved survival is correlated with reductions in morbidity for the elderly, then illness may be compressed into the end of life, as posited by the "compression of morbidity" hypothesis (Fries 1980). On the other side, it is also true that medical interventions tend to keep alive those who are in worse health (Zeckhauser, Sato, and Rizzo 1985), which suggests the possibility that the longer-lived elderly could be sicker for a longer period. The net effect of rising longevity on age-specific morbidity is an empirical question. According to the National Long Term Care Survey, the share of Americans with severe disabilities decreased from 26.2 to 19.7 percent between 1982 and 1999 (Manton and Gu 2001). Milligan and Wise (2011) find a strong within-country correlation between declining mortality and improved self-assessed health for several European countries. Thus, the empirical record suggests that better health in terms of both improved survival and reduced morbidity could tend to raise age-specific rates of labor force participation. Changes in occupational structure which lower the physical demands of work also can increase participation.

Higher incomes tend to increase the demand for leisure, in the form of fewer hours per week and, especially recently, as a block at the end of life (Costa 1998; Murphy and Topel 2006). Furthermore, several factors might give rise to a negative interaction between improved survival and employment, at least for some sub-groups. For example, the reduced selection effect of mortality might also increase the proportion of the cohort that is less valued in employment (because of less stamina, ambition, education, and the like), reducing agespecific labor force participation. Alternatively, if firms have pyramid-like organizational structures with many jobs at entry and fewer at higher levels in the hierarchy—such as the military's "up or out" policy regarding age and promotion of officers-then increases in survival will lead to crowding at higher levels of the pyramid and lower rates of participation. Moreover, a sharp rise in employment rates for women, at wages that were often below those paid to men, might have led to some decrease in the demand for men's labor.

On net, which of these forces has predominated over the past century, and which are likely to predominate in the future? Estimates of what we call "expected labor force participation" can help answer this question.

\section{Calculating Expected Labor Force Participation}

We define "expected labor force participation" (XLFP) as the total years an individual is expected to participate in the labor force, based on period estimates of survival, and labor force participation by gender and age. That is 


$$
X L F P_{j t}=\sum_{i=1}^{100} \pi_{i j t} L_{i j t},
$$

where $L_{i j t}$ is the LFP rate for age $\mathrm{i}$ and gender $\mathrm{j}$ in year $\mathrm{t}$, weighted by probability of survival to age $\mathrm{i}\left(\pi_{i j t}\right)$. It is necessary to examine men and women separately because of the large upsurge in female labor force participation between the 1950s and 2000 (Goldin 1986, 1990; Costa 2000). Our calculations rely on labor force participation rates from decennial censuses (1900-1930) and the Current Population Survey (1942-2007). As in the earlier estimates of life expectancy, we can calculate both "period" expected labor force participation, which is based on the age-specific labor force participation rates prevailing at a certain point of time, or the actual realized labor force participation rates for a birth cohort; these estimates will differ when age-specific labor force participation rates are changing over time.

Changes in lifetime expected labor force participation can be decomposed into two factors: changes in survival to given ages and changes in age-sex-specific rates of labor force participation. For example, we calculate the effect of improving survival, holding agespecific labor force participation rates constant at their 2007 values. We also calculate the effect of changing rates of labor force participation, holding survival rates constant. ${ }^{3}$

Our work is related to the literature on expected lifetime work hours (Hazan 2009) and worklife expectancy (Smith 1982), including the Bureau of Labor Statistics' worklife estimates for the U.S. population from the 1950s through the early 1980s. ${ }^{4}$ As far as we are aware, this paper is the first to produce worklife estimates for the United States covering the period 1900 to 2007, decompose those changes into survival and age-sex-specific labor force participation effects, and to estimate worklife expectancy relative to life expectancy at birth for a broader range of countries in recent decades.

\section{U.S. Expected Labor Force Participation Since 1900}

In the early twentieth century most of the increase in life expectancy arose from the dramatic decrease in mortality at young ages. This change first increased the years of youth dependency for these cohorts, and then increased expected labor force participation-the expected number of years that an individual will be in the labor force if he or she participates at the average LFP rate for each sex and age in a given year.

Figure 4A shows that years of expected labor force participation at birth for U.S. males increased by a third—from about 30 to 40 years—between 1900 and 1950. For the most recent half century, however, increases in survival have been offset by decreasing agespecific labor force participation rates for men, causing expected lifetime labor force participation to be relatively constant at about 40 years. Because life expectancy at birth has continued to increase, male expected labor force participation as a fraction of expected years

\footnotetext{
${ }^{3}$ These are decompositions 1B and 2B, respectively, in Appendix table 7. Alternative calculations, using 1900 as the base year (decompositions $1 \mathrm{~A}$ and $2 \mathrm{~A}$ ), show similar results.

${ }^{4}$ In other pre-existing work in this area, Hunt and colleagues (1997) update worklife estimates for the U.S. based on 1992-1993 labor force participation rates. Millimet and colleagues (2003) use a regression framework. In related research, Hazan (2009) estimates lifetime working hours for U.S. men born between 1840 and 1970 and for the U.S. population born between 1890 and 1970.
} 
of life has declined, as shown in Figure 4B. Table 1 shows that in the United States between 1900 and 2000, male participation increased from 30 to 40.5 years, female participation from 6.4 years to 34.4 years, and for the total population from 18.5 to 37.4 years. This increase in years of expected labor participation is two-thirds of the total gain in life expectancy at birth of 28.2 years over the twentieth century.

How much of this change is attributable just to longer life expectancies? If we hold agespecific rates of labor force participation constant, but allow survival rates to grow at the actually observed pace, the rise in life expectancy alone would have increased expected labor force participation by 13.3 years for males and by 10.8 years for females since 1900 . (See Table 1.) The effect of mortality decline was concentrated in the first half of the twentieth century. Indeed, for men, the ratio of years of expected labor force participation to life expectancy at birth-holding age-specific labor force participation rates constant but allowing survival rates to vary-was relatively constant at 54 percent from early in the twentieth century until about 1970 . At that point, it began a slow but seemingly inexorable decline, now falling to about 50 percent.

Actual years of expected labor force participation, reflecting both survival effects and changes in age-specific labor force participation rates, have also begun to decline. The ratio of years of expected labor force participation to life expectancy at birth (XLFP/LE $\mathrm{X}_{0}$ ) has declined for U.S. men from 62.6 percent in 1900 to 51.6 percent in 2007 . That same ratio for women increased from 12.7 percent in 1900 to 43.2 percent in 2000 , before declining slightly to 41.5 percent by 2007 . For the overall U.S. population, years of expected labor force participation divided by life expectancy at birth peaked at 48.6 percent in 2000 and declined slightly to 46.3 percent by 2007 (as shown in Table 1 and earlier in Figure 4B).

Since 1950, increases in survival and declines in age-specific participation rates of men tended to offset one another. For example, between 1950 and 2007, labor force participation rates of men ages $45-54$ declined from 95.8 percent to 88.2 percent, but survival to age 50 increased from 84.1 to 92.2 percent, so the total expected years in the labor force between ages 45 and 55 remained eight years. ${ }^{5}$

For women, increases in years of expected labor force participation mostly reflect increases in age-specific rates of labor force participation, especially after 1950. Accordingly, for women the ratio of years of expected labor force participation to life expectancy at birthholding age-specific labor force participation rates constant but allowing survival rates to vary - has declined slowly but steadily from about 45 percent in the first few decades of the twentieth century to about 40 percent. The increase in female labor force participation since the late 1950s could be considered primarily a one-time substitution from unpaid home production to paid work outside the home (Goldin 1990; Costa 2000). If so, then the decrease in years of expected labor force participation for women in the United States since

\footnotetext{
${ }^{5}$ For the detailed data behind these calculations across the range of ages, for both men and women, see Appendix Figure $2 \mathrm{~A}$ and Appendix Table 7, which offer alternative decompositions of changes in both male and female labor force participation. Appendix Table 7 also shows that holding age-specific labor force participation rates constant (at either their 1900 or 2007 values) would have led to a larger increase in male expected labor force participation than actually observed. Appendix Figure 2B shows how closely the actual expected labor force participation rates for women tracks the rate that would have prevailed if survival had been at 2007 levels, but age-specific labor force participation rates had increased as they actually did from 1900 to 2007.
} 
2000 would reflect relative completion of the one-off change and the beginning of a similar trend as seen for men - that is, a decline of years in the labor force as a share of life expectancy at birth.

Taking into account the decrease in the intensive margin-annual hours worked per fulltime worker - tends to reinforce the conclusion that expected work life has declined as a fraction of life expectancy at birth. Hazan (2009) estimated lifetime work hours over the past century conditional on survival to age 5. We adapt Hazan's data to life expectancy at birth to calculate years of expected labor force participation adjusted for hours worked. (See Table 1 for results and Appendix for details of our calculations.)

Calculation of a century-long trend in expected years of labor force participation in other high-income countries is not possible because there is no reliable source for internationally comparable labor force participation rates before 1980. Given the similarities in trends of both survival and labor force participation across these 15 countries for the available years, we suspect the trend of declining expected labor force participation as a share of life expectancy at birth that we found for the United states reflects a broad and robust trend that countries experience as they reach high life expectancy levels. Indeed, with the sole exception of the Netherlands, the ratio of years of expected labor force participation to life expectancy at birth has declined since 1980 for males in all 15 other high-income countries in our analyses. ${ }^{6}$ Adjusting for a decline in work hours would reinforce this trend.

\section{Demographic Transition across Stages of Economic Development}

The demographic transition traces out a pathway, with many societies arrayed along earlier phases of the transition roughly and imperfectly in accordance with their per capita incomes. Many developing countries are currently experiencing the original demographic transition. For example, Table 2 shows that between 1990 and 2010, the share of years lived past 65 as a percentage of increase in life expectancy at birth was only a little over a third in Vietnam and Brazil, and less than a quarter in Bangladesh - comparable to levels a century earlier in today's high-income countries.

Improving health and increasing life expectancy at birth clearly can contribute to better living standards for the world's poor (World Health Organization 2002). Data on labor force participation for developing countries is not always reliably comparable across countries and over time. Nevertheless, the importance of improved survival for gains in expected labor force participation at early stages of the longevity transition can be illustrated with extant data. For example, in 1980 only 70 percent of Indonesian men survived to age 45; by 2007 , 90 percent did. This improved survival added 10 years to expected labor force participation rates for Indonesian males between 1980 and 2007. As a result, expected labor force participation rates for Indonesian males rose to 43.7 years, which was 64.5 percent of life expectancy at birth in 2007.

\footnotetext{
${ }^{6}$ The appendix tables provide calculations of expected labor force participation across 15 countries since 1980; see Table 8 in the online appendix available with this paper at <http://e-jep.org>. Milligen and Wise (2011, p. 17) examine the age at which male mortality was 1.5 percent in 1977 and 2007, finding that at that age almost 90 percent of UK men were employed in 1977, but by 2007, only 30 percent were.
} 
China and India are especially important cases to consider, given their large populations and relatively rapid economic development. In India, the share of years lived past 65 as a percentage of increase in life expectancy at birth was barely one-quarter (as shown in Table 2 ) in the most recent 20 year period. For China, that share was 52 percent for men and 41 percent for women in the 1990-2010 period.

China's position reflects the rapidity of its demographic transition since the early 1970s and its achievement of relatively high levels of health despite low per capita income by the end of the Mao era (Banister 1987; Wang 2011). Indeed, despite the higher death rates associated with the Great Leap Famine of 1959-1961, China's growth in life expectancy from 35 40 in 1949 to 65.5 in 1980 ranks as the most rapid sustained increase in documented global history. ${ }^{7}$ These earlier health improvements and growth of the workingage population contributed to China's unprecedented economic growth for the past quarter century. Wang and Mason (2008) estimate that between 1982 and 2000, about 15 percent of China's rapid growth in output per capita stemmed from the demographic dividend. (Bloom and Williamson [1998] estimate that one-quarter to one-third of the growth rates in the "East Asian miracle" stemmed from the demographic dividend.) Although the pace of mortality decline in China has slowed, it continues: Chinese life expectancy increased between 1990 and 2010 from 69.9 to 76.8 for women and from 66.9 to 72.5 for men.

With a rapid demographic transition to relatively low mortality and low fertility, China's population is now aging (Peng 2011). Many policy challenges loom as China establishes social and economic institutions commensurate with its transition to a middle-income, market-based economy with a large elderly population (Eggleston and Tuljapurkar 2010; Chen, Eggleston, and Li 2011). One additional challenge for China in reducing the growthslowing potential of the new demographic transition is China's increasing burden of chronic disease. Fueled by rapid urbanization, increases in high-fat and calorie-rich diets, reductions in physical activity, unabated male smoking and other factors, prevalence of chronic disease has quickly caught up in China with that of high-income countries. For example, the agestandardized prevalence of diabetes among adults in China was 9.7 percent in 2007-2008, more than 3 times reported prevalence in 1994 (Yang et al. 2010), comparable to prevalence in the US (8.3 percent overall in 2010, and 11.3 percent among adults; CDC 2011), and higher than the OECD average (OECD 2011).

The timing and the rapidity of the longevity transition has varied across countries and regions. For example, in Japan between 1950 and 1970, only 13.1 percent of increase in male life expectancy at birth was realized after age 65; for women, that figure was 17.3 percent. During the 1990 to 2009 period, Japan led the world in the new demographic transition, with the share of gains in life expectancy at birth realized after age 65 reaching 72.7 percent for men and 87 percent for women (again, as shown in Table 2).

\footnotetext{
${ }^{7}$ Miller, Eggleston and Zhang (2011) assess the relative importance of various explanations proposed for these gains, including better nutrition, widespread public health interventions, improved access to medical care, and increases in educational levels. They find that gains in education and public health campaigns jointly explain 25-32 percent of the crude death rate decline under Mao, and similar proportions of the dramatic reductions in infant and under-five mortality in that period.
} 
The original and the new demographic transitions are inextricably intertwined with the evolution of social and economic institutions (Aoki 2011). Evidence is mounting that no society at an advanced stage of economic development can presume that further gains in longevity will contribute to growth of per capita income under currently prevailing institutions. For example, Lee and Mason (2011) compare the average age of consumption to the average age of labor income across a large group of countries for which they and their international collaborators have collected detailed generational accounts, including the value of assets and transfer wealth from social support programs (but not including bequests or value of non-market labor). They find that for developing countries, net transfers flow strongly downward from older to younger ages. However, in a "sea change" analogous to what we call the new demographic transition, "the direction of intergenerational transfers in the population has shifted from downward to upward, at least in a few leading rich nations" including Germany, Austria, and Japan (Lee and Mason 2011, p. 116). Although the LeeMason estimates are cross-sectional, the link to the longevity transition is clear: for the 13 countries that overlap between their dataset and ours, there is a strong negative correlation $(-0.89)$ between the share of gains in life expectancy over the past 20 years that were realized after age 65 , and the current number of years by which the average age of income exceeds the average age of consumption. In other words, the more the gains in life expectancy are concentrated in traditional retirement years, the closer the intergenerational transfers are to being upward rather than downward.

For a broader group of 107 countries, Bloom, Canning, and Fink (2010) calculate counterfactual annual growth rates of per capita income between 1960 and 2005, using 2005-50 projections of demographics. The results vary depending on the level of economic development. They find that in most non-OECD countries, declining youth dependency would more than offset increasing old-age dependency. However, about half of countries would have grown more slowly using 2005-50 projections of demographics. Among 26 OECD countries analyzed, 25 of them (Turkey is the exception) would have had lower economic growth-averaging 2.1 rather than 2.8 percent per year-under the counterfactual of 2005-50 demographic change.

\section{Policy Implications of the New Demographic Transition}

Historically, adults produced more than they consumed and supported children. With such a pattern in place, the increase in proportion of the population in older years implied by the demographic transition might have been thought to shift out the social budget constraint as people expanded their number of years worked. However, "a funny thing happened along the way: societies invented retirement... and the economic consequences of population aging are now viewed with alarm" (Lee and Mason 2011, p.115).

Retirement, a relatively new phenomenon in human history, can be viewed as a response to many economic and social changes. Contributing factors include the shift from selfemployment on farms or small businesses to wage and salary status; more rapid technological change, resulting in more rapid obsolescence of human capital (alongside compensation packages that often under-pay at the beginning and over-pay at the end of a career [Lazear 1981]); the introduction of a variety of health and welfare programs for the 
elderly which discourage work; an income-driven increase in the demand for leisure, with the diminished marginal value of an even shorter work week overtaken by the efficiency gains of a block of leisure at the end of life; and, in times of high unemployment, public concern about job opportunities for younger workers.

Will the new demographic transition inevitably lead to slower economic growth? As people foresee longer lives, they might choose to work longer, save more, and/or invest in human capital in sufficient amounts and innovative enough ways that longer lives continue to contribute to increased prosperity. In this spirit, Bloom, Canning, and Fink (2010) assert that "the problem of population ageing is more a function of rigid and outmoded policies and institutions than a problem of demographic change per se" (p. 607).

It is not clear, however, that the United States or other high-income countries even further along in the new demographic transition are reshaping their policies and institutions sufficiently in response to the longevity transition. Although both the United States and France have increased the age of retirement or age to qualify for early retirement, social welfare systems across the high-income countries of the world continue to give strong incentives for earlier, rather than later, retirement (Gruber and Wise 1998). Between 1965 and 2005, the correlation between change in male life expectancy at birth and change in retirement age is actually negative: -0.21 (Bloom, Canning, and Fink 2010, p.591). This trend cannot continue indefinitely: longer and longer retirement lives are not consistent with continued increases in per capita income unless there are significant increases in savings, investment, and productivity. It is ironic that the same phenomenon that led to higher GDP per capita_namely higher life expectancy_ can now decrease GDP per capita.

Successful navigation of the new demographic transition calls for a combination of policies to change the incentives for savings and investment (including in human capital) earlier in the lifecycle and working later in the lifecycle. Two forces in particular might move the society in that direction: improvement in health, and reductions in the transfers that the elderly can expect to receive from the young.

Public policy should encourage higher labor force participation for the elderly, both by reducing the disadvantages that employers face when employing older workers and by providing enhanced incentives to individuals to continue to work. "People cannot expect to finance 20-25 year retirements with 35-year careers," John B. Shoven noted. "It just won't work. Not in Greece [or] the United States ... Eventually, we are going to have to increase retirement ages" (as quoted in Haven 2011). However, increasing labor force participation for the 65-plus age group alone probably won't make a big difference: even a doubling of those rates from their 2007 levels of 12.6 for women and 20.5 for men would not bring the US ratio of expected labor force participation to life expectancy at birth back to its 2000 level. Increased participation by men $50-64$ is needed.

Public policy might also seek to improve productivity, with an emphasis on education and building human capital early in the life-cycle, and on investment to reduce morbidity and improve the physical ability to work later in life. Whether compression of morbidity later in life will continue depends on whether improvements in medical technology and in the socio- 
economic determinants of health are offset by adverse trends such as increasing obesity. A potentially promising focus here would be to consider investments in public health and medical technologies that reduce morbidity and improve quality of life, as well as more focus on medical innovations that reduce costs of care. (One example of a policy consistent with both objectives would be expansion of palliative care as a substitute for what can otherwise be extremely expensive end-of-life care in a hospital-especially in countries where the concept of hospice services is relatively new, such as China.)

Finally, increased savings, investment, and capital formation could help in fueling endogenous growth (Lucas 1988; Romer 1990). U.S. personal savings rates have been low for many decades. Increasing the savings rate of individuals before they retire would ameliorate the potential adverse impact of longevity on economic growth. Countries will need to make fiscally realistic structural changes to entitlement programs - such as Medicare and Social Security in the United States - to support acceptable living standards and improvements in health.

High-income societies are now facing a new demographic transition: the longevity transition. They must decide how to respond to mortality decline when almost all of the decline will occur late in life. Additional increases in life expectancy will result in further declines in expected labor force participation as a percentage of life expectancy at birth, unless there is a significant rise in labor force participation rates across both middle and older ages. Of course, increased life expectancy has great value independent of its relationship to per capita income (Murphy and Topel 2006). The original demographic transition gave society a "demographic gift" of higher per capita incomes (Bloom and Williamson 1998) without much need for a policy response, but the new demographic transition requires politically difficult policies if societies wish to preserve a positive relationship running from increased longevity to greater prosperity.

\section{Acknowledgments}

The authors gratefully acknowledge constructive comments from the Journal of Economic Perspectives editors, as well as from Judith Banister, Richard Zeckhauser, and participants at a Stanford University seminar. We extend our appreciation and thanks to Loraine West, Daniel Goodkind, and Andrea Miles at the U.S. Bureau of the Census for graciously providing country life tables from the U.S. Bureau of the Census International Data Base. We also thank Shannon Davidson and Shaowen Ang for excellent research assistance. Karen Eggleston gratefully acknowledges research funding from the Shorenstein Asia-Pacific Research Center at Stanford University; and the Stanford Center on the Demography and Economics of Health and Aging seed grant under grant number AG017253 from the National Institutes of Health. The funders had no role in study design; in the collection, analysis and interpretation of data; in the writing of the report; and in the decision to submit the article for publication.

\section{References}

Aoki, Masahiko. The Five-Phases of Economic Development and Institutional Evolution in China and Japan. Presidential Lecture at the XVIth World Congress of the International Economic Association; 2011.

Banister, Judith. China's Changing Population. Stanford University Press; 1987.

Barker, David J. “The Fetal and Infant Origins of Adult Disease.”. British Medical Journal. 1990; 301(6761):1111. [PubMed: 2252919]

Bell, Felicitie C.; Miller, Michael L. "Life Tables for the United States Social Security Asia 19002100" Actuarial Study No. 120, Social Security Administration Office of the Chief Actuary, SSA 
Pub. No. 11-11536. 2005. Available from: http://www.socialsecurity.gov/OACT/NOTES/ s2000s.html [downloaded 12 March 2012]

Bloom, David E.; Canning, D.; Fink, G. "Implications of Population Ageing for Economic Growth". Oxford Review of Economic Policy. 2010; 26(4):583-612.

Bloom, David E.; Canning, D.; Sevilla, J. The Demographic Dividend: A New Perspective on the Economic Consequences of Population Change. Vol. Vol. 5. Rand Corporation; 2003.

Bloom, David E.; Williamson, JG. "Demographic Transitions and Economic Miracles in Emerging Asia”. The World Bank Economic Review. 1998; 12(3):419-455.

Chen, Qiulin; Eggleston, Karen N.; Ling, Li. "Demographic Change, Intergenerational Transfers, and the Challenges to Social Protection Systems in China,". forthcoming in Demographic Transition and Inclusive Growth in Asia. 2011

Centers for Disease Control and Prevention (CDC). Atlanta, GA: CDC; 2011. "2011 National Diabetes Fact Sheet". Available from http://www.cdc.gov/diabetes/pubs/pdf/ndfs_2011.pdf [downloaded 12 March 2012]

Costa, Dora L. The Evolution of Retirement: An American Economic History, 1880-1990. Chicago, IL, USA: University of Chicago Press; 1998.

Costa, Dora L. "From Mill Town to Board Room: The Rise of Women's Paid Labor.”. Journal of Economic Perspectives. 2000; 14(4):101-122.

Cutler, David; Deaton, Angus; Lleras-Muney, Adriana. “The Determinants of Mortality,”. Journal of Economic Perspectives. 2006; 20(3):97-120.

Davis, Kingsley. “The World Demographic Transition.”. Annals of the American Academy of Political and Social Science. 1945; 237:1-11.

Eggleston, Karen N.; Tuljapurkar, Shripad, editors. Aging Asia: Economic and Social Implications of Rapid Demographic Change in China, Japan, and South Korea. Stanford University Walter H: Shorenstein Asia-Pacific Research Center series with Brookings Institution Press; 2010.

Fogel, Robert W. "Economic Growth, Population Theory, and Physiology: The Bearing of Long-term Processes on the Making of Economic Policy.”. American Economic Review. 1994; 84(3):369395.

Fries, James F. “Aging, Natural Death, and the Compression of Morbidity.”. New England Journal of Medicine. 1980; 303(3):130-135. [PubMed: 7383070]

Fuchs, Victor R. “'Provide, Provide': The Economics of Aging.”. In: Rettenmaier, Andrew J.; Saving, Thomas R., editors. Medicare Reform: Issues and Answers. The University of Chicago Press, 1999; 1999. p. 15-36.

Galor, Oded; Weil, David N. "The Gender Gap, Fertility, and Growth.”. American Economic Review. 1996; 86(3):374-387.

Gruber, Jonathan; Wise, David A. Social Security Programs and Retirement around the World. Chicago, IL, USA: University of Chicago Press; 1998.

Guinnane, Timothy W. “The Historical Fertility Transition: A Guide for Economists.”. Journal of Economic Literature. 2011; 49(3):589-614.

Goldin, Claudia. “The Female Labor Force and American Economic Growth: 1890 to 1980,”. In: Engerman, Stanley; Gallman, Robert, editors. Long-Term Factors in American Economic Growth; Conference on Income and Wealth; Chicago: University of Chicago Press; 557-604; 1986.

Goldin, Claudia. Understanding the Gender Gap: An Economic History of American Women. New York-Oxford: Oxford University Press; 1990.

Haven, Cynthia. "Stanford economist: How do we 'get off this path of deficits as far as the eye can see?'”. Stanford Report. 2011 Aug 2. Available at http://news.stanford.edu/news/2011/august/ shoven-debt-qanda-080211.html

Hazan, Moshe. "Longevity and Lifetime Labor Supply: Evidence and Implications,". Econometrica. 2009; 77(6):1829-1863.

Human Mortality Database. Germany: University of California, Berkeley (USA), and Max Planck Institute for Demographic Research; Available at www.mortality.org 
Hunt, Tamorah; Pickersgill, Joyce; Rutemiller, Herbert. "Recent Trends in Median Years to Retirement and Worklife Expectancy for the Civilian U.S. Population (Prepared Using 1998/99 BLS Labor Force Participation Rates).”. Journal of Forensic Economics. 2001; 14(3):203-227.

Lazear, Edward P. “Agency, Earnings Profiles, Productivity, and Hours Restrictions.”. American Economic Review. 1981; 71(4):606-620.

Lee, Ronald D. “The Demographic Transition: Three Centuries of Fundamental Change.”. Journal of Economic Perspectives. 2003; 17(4):167-190.

Lee, Ronald D.; Reher, David S. "Introduction: The Landscape of Demographic Transition and its Aftermath". Population and Development Review. 2011; 37:1-7. [PubMed: 21714197]

Lee, Ronald D.; Andrew, Mason. "Generational Economics in a Changing World". Population and Development Review. 2011; 37:115-142. [PubMed: 21804657]

Lee, Ronald D.; Shripad, Tuljapurkar. "Death and Taxes: Longer Life, Consumption, and Social Security”. Demography. 1997; 34(1):67-81. [PubMed: 9074832]

Lucas, Robert E. "On the Mechanics of Economic Development”. Journal of Monetary Economics. 1988; 22(1):3-42.

Manton, Kenneth G.; Xiliang, Gu. "Changes in the Prevalence of Chronic Disability in the United States Black and Nonblack Population Above Age 65 from 1982 to 1999". Proceedings of the National Academy of Sciences. 2001; 98(11):6354-6359.

Miller, NGrant; Eggleston, Karen N.; Qiong, Zhang. "Understanding China’s Mortality Decline under Mao: A Provincial Analysis, 1950-1980,”. Stanford University Asia Health Policy Program working paper. 2011 Sep.

Milligan, Kevin; Wise, David A. Introduction to "Social Security and Retirement around the World: Historical Trends in Mortality and Health, Employment, and Disability Insurance Participation and Reforms”. National Bureau of Economic Research working paper; 2011. p. 16719

Millimet, Daniel L.; Nieswiadomy, Michael; Ryu, Hang; Slottje, Daniel. "Estimating Worklife Expectancy: An Econometric Approach.”. Journal of Econometrics. 2003; 113(1):83-113.

Murphy, Kevin M.; Topel, Robert H. "The Value of Health and Longevity.”. Journal of Political Economy. 2006; 114(4):871-904.

OECD. Health at a glance 2011: OECD Indicators. Organization for Economic Cooperation and Development; 2011. Available from: http://www.oecd.org/dataoecd/6/28/49105858.pdf [downloaded 12 March 2012]

Peng, Xizhe. “China’s Demographic History and Future Challenges.”. Science. 2011; 333(6042):581587. [PubMed: 21798939]

Romer, Paul M. "Endogenous Technological Change.”. Journal of Political Economy; Part 2: The Problem of Development: A Conference of the Institute for the Study of Free Enterprise Systems; 1990 Oct. p. S71-S102.

Smith, Shirley J. "New Worklife Estimates Reflect Changing Profile of Labor Force.". Monthly Labor Review. 1982; 105:15.

Swift, Robyn. "The Relationship between Health and GDP in OECD Countries in the Very Long Run”. Health Economics. 2011; 20(3):306-322. [PubMed: 20217835]

Wang, Feng. "The Future of a Demographic Overachiever: Long-Term Implications of the Demographic Transition in China". Population and Development Review. 2011; 37:173-190. [PubMed: 21280370]

Wang, Feng; Andrew, Mason. “The Demographic Factor in China's Transition.”. In: Brandt, Loren; Rawski, Thomas G., editors. Chapter 5 in China's Great Economic Transformation. Cambridge: Cambridge University Press; 2008. p. 136-166.

World Health Organization. Macroeconomics and Health: Investing in Health for Economic Development: Report of the Commission on Macroeconomics and Health. World Health Organization (WHO; 2002.

Yang W, Lu J, Weng i, Jia W, Ji L, Xiao J, Shan Z, Liu J, Tian H, Ji Q, Zhu D, Ge J, Lin L, Chen L, Guo X, Zhao Z, Li Q, Zhou Z, Shan G, He J. Prevalence of Diabetes among Men and Women in China. New England Journal of Medicine. 2010; 362(12):1090-1101. [PubMed: 20335585] 
Zeckhauser, Richard J.; Sato, Ryuzo; Rizzo, John. Health Intervention and Population Heterogeneity: Evidence from Japan and the United States. National Institute for Research Advancement; 1985 Dec. "Hidden Heterogeneity in Risk: Evidence from Japanese Mortality,"; p. 23-131. 
A: Life Expectancy at Birth Since 1900

US and 16 Other High Income Countries

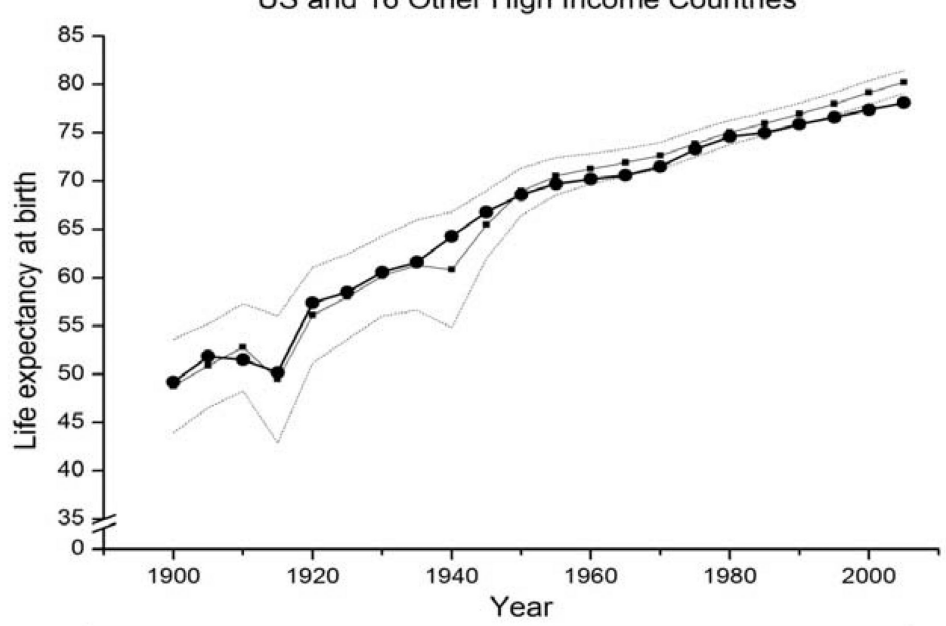

$\longrightarrow$ us

- 16 high-income country average

One standard deviation above and below the 16 -country average

B: Percent of Birth Cohort Expected to Survive to Age 65 Since 1900 US and 16 Other High Income Countries

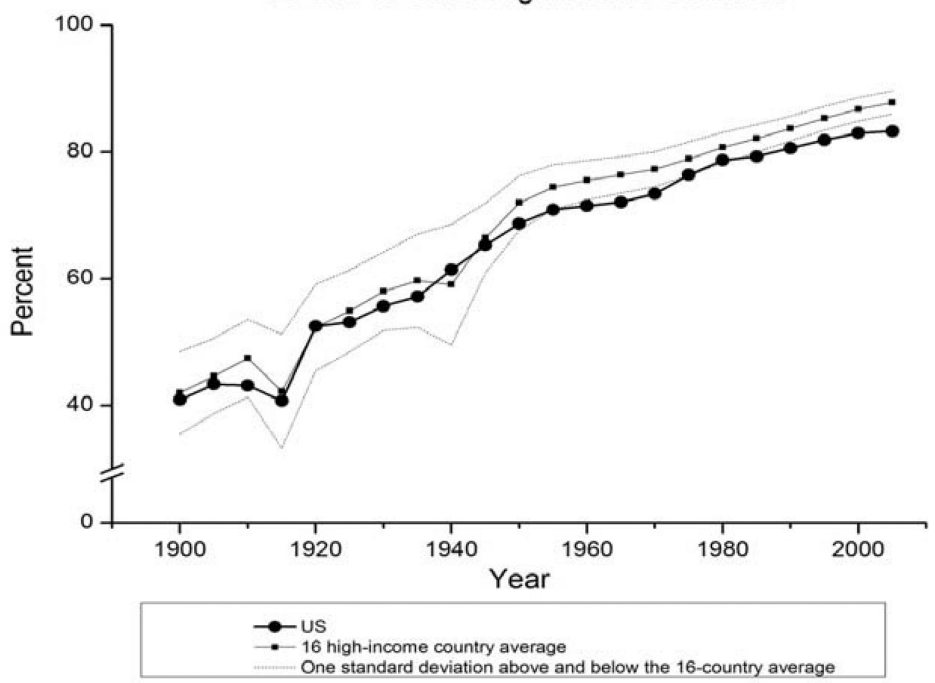

Figure 1.

A: Life Expectancy at Birth Since 1900 US and 16 Other High Income Countries B: Percent of Birth Cohort Expected to Survive to Age 65 Since 1900 US and 16 Other High Income Countries 


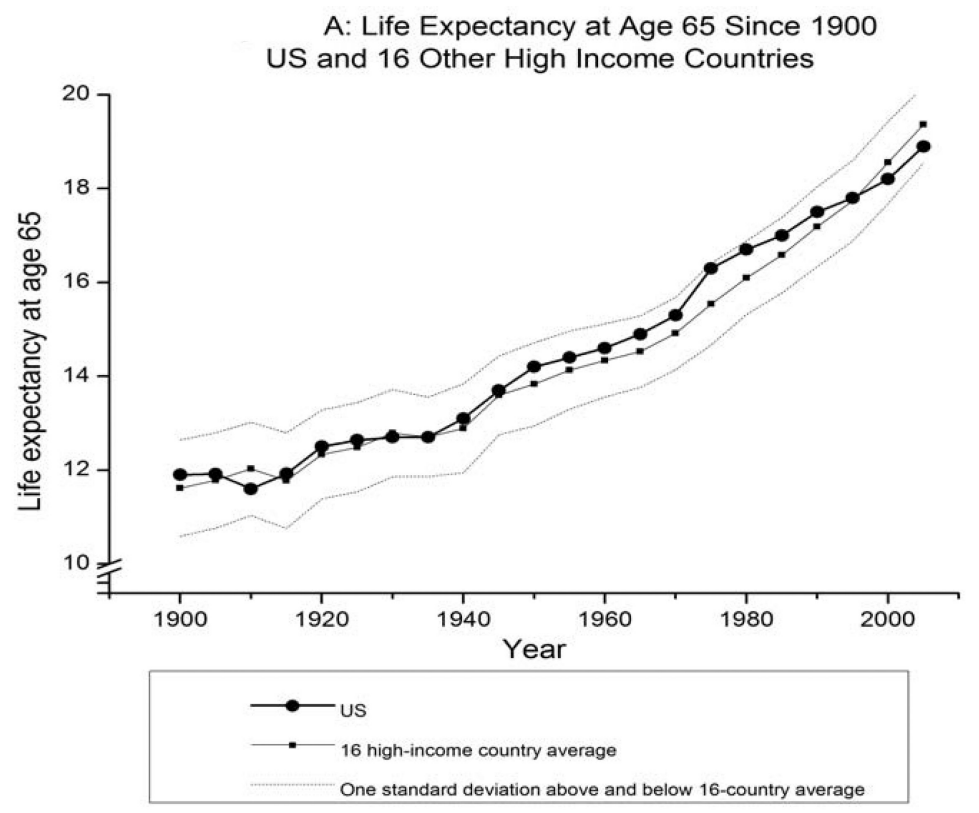

B: Share of Gains in Life Expectancy at Birth Realized after Age 65 Since 1900 US and 16 Other High Income Countries

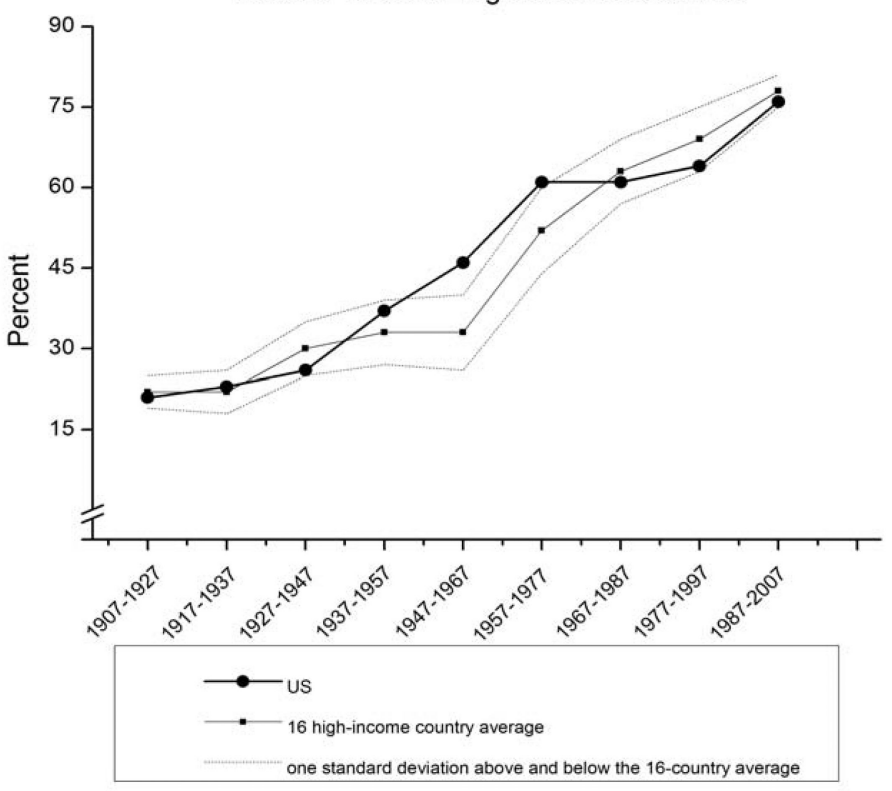

Figure 2.

A: Life Expectancy at Age 65 Since 1900 US and 16 Other High Income Countries B: Share of Gains in Life Expectancy at Birth Realized after Age 65 Since 1900 US and 16 Other High Income Countries 


\section{Decrease in Death Rates by Age Group in England and Wales, 1900-04 to 1950-54 and 1950-54 to 2000-04}

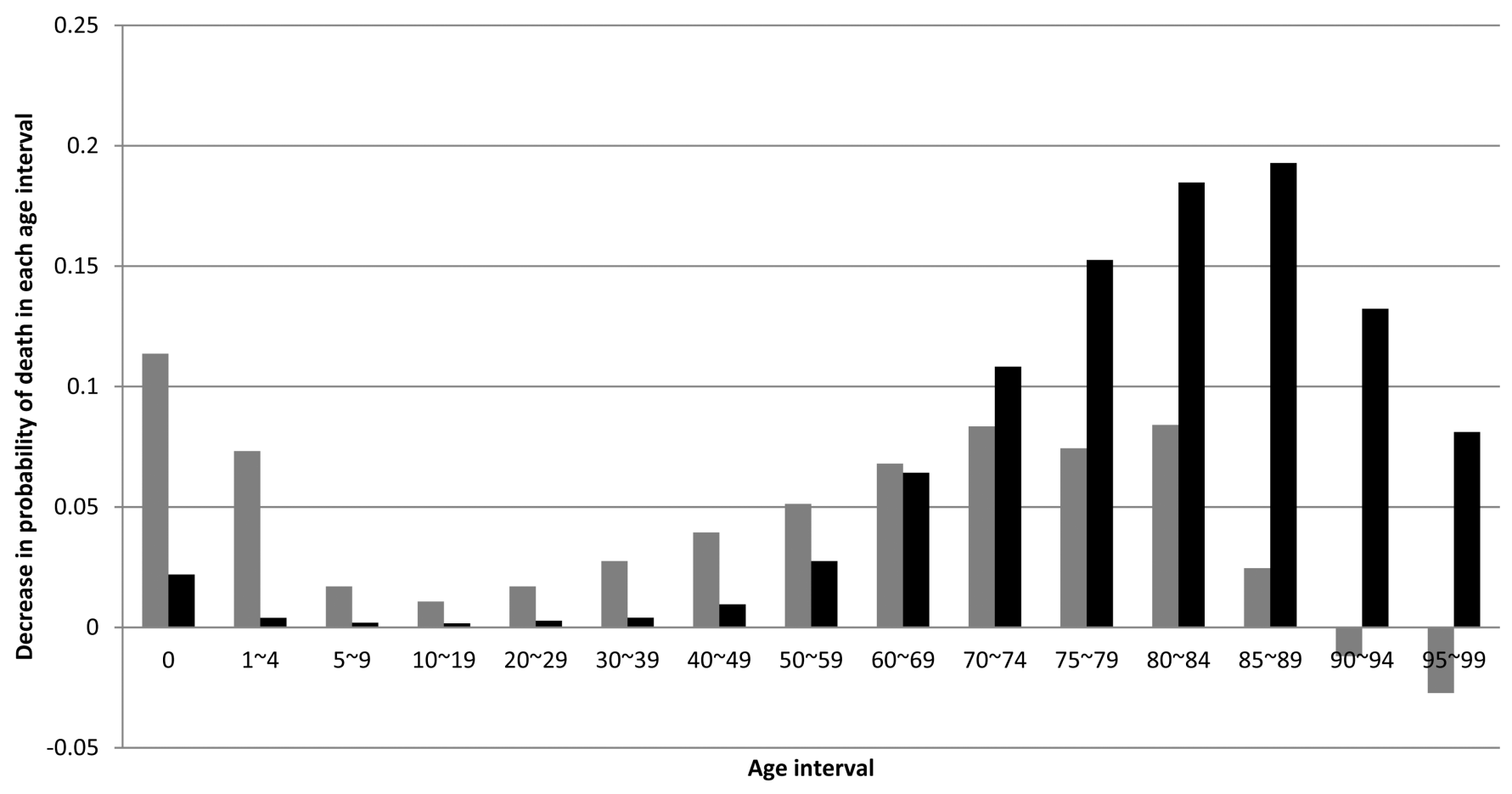

Decrease in death rates between 1900-04 and 1950-54

Decrease in death rates between 1950-54 and 2000-04

Figure 3.

Decrease in Death Rates by Age Group in England and Wales, 1900-04 to 1950-54 and 1950-54 to 2000-04 

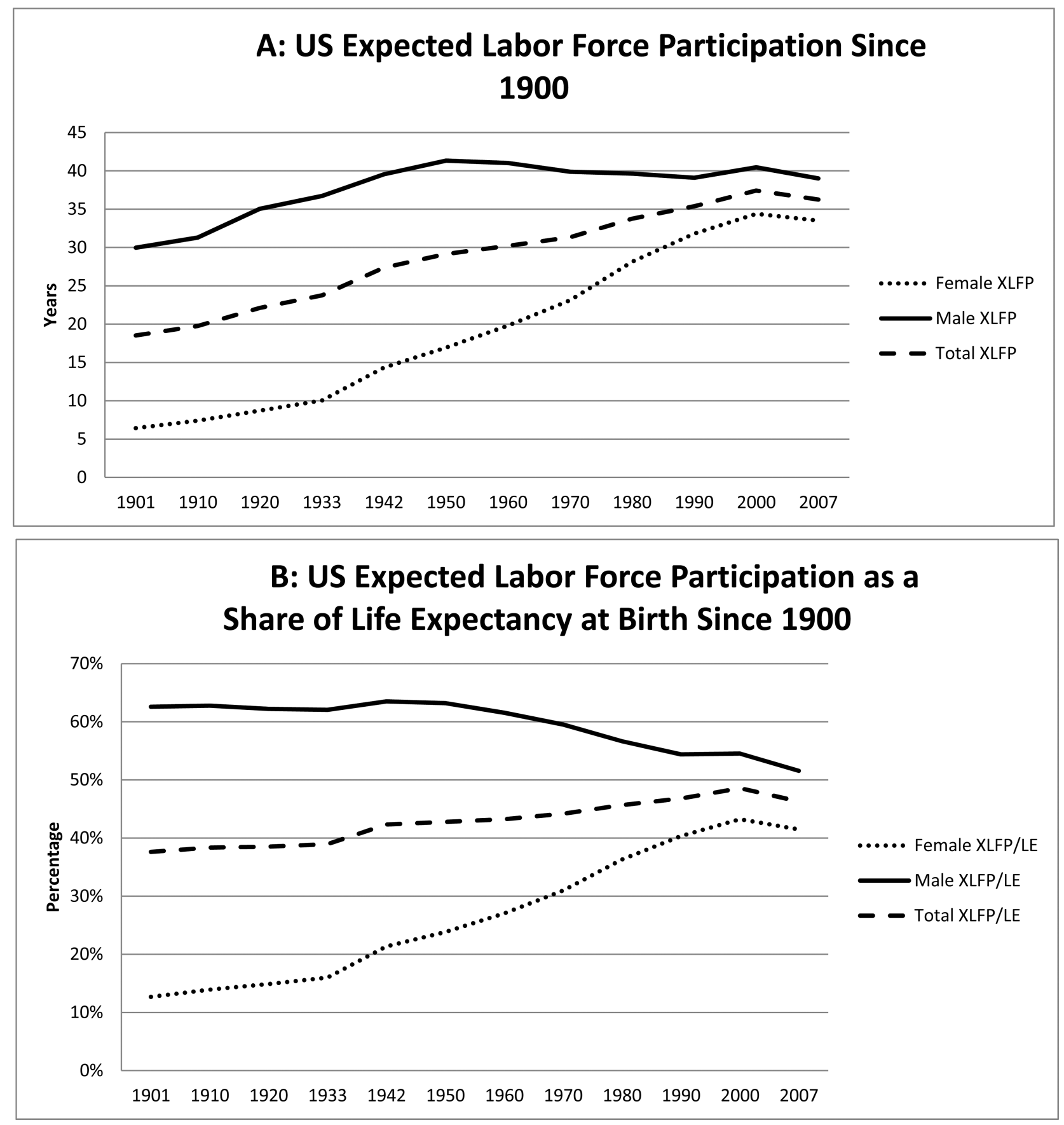

Figure 4.

A: US Expected Labor Force Participation Since 1900

B: US Expected Labor Force Participation as a Share of Life Expectancy at Birth Since 1900 


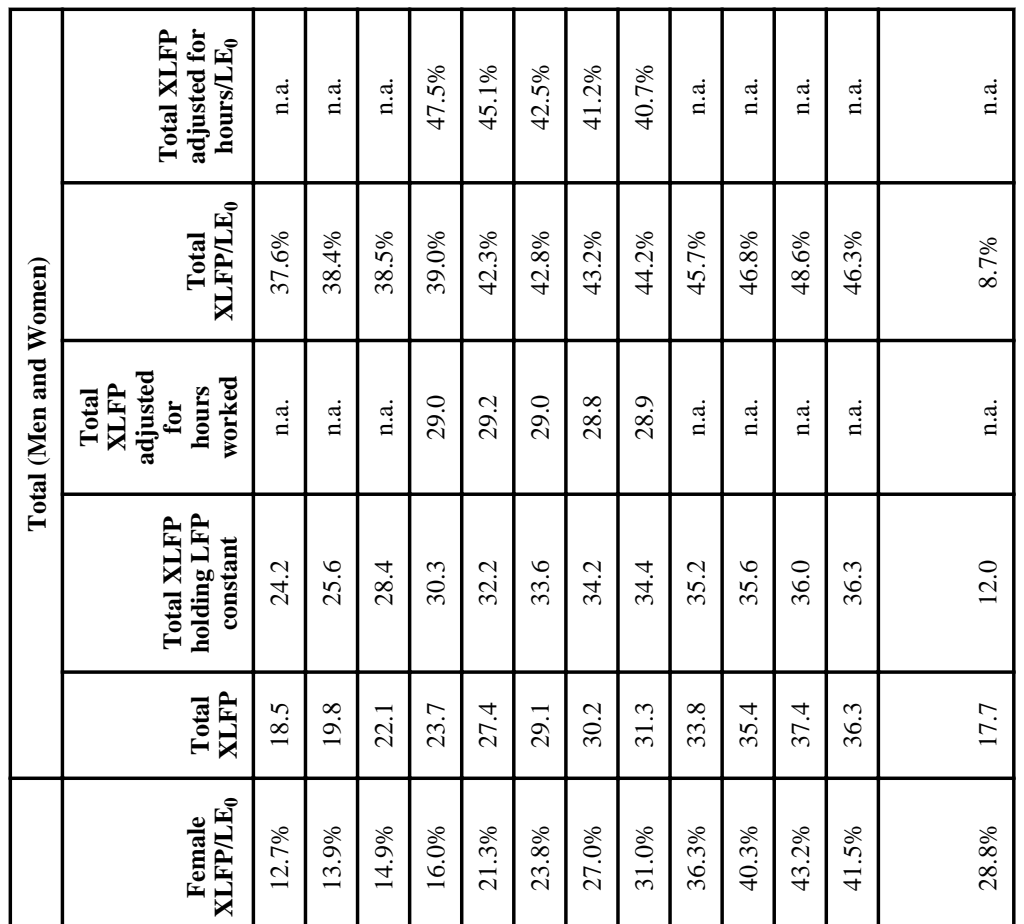

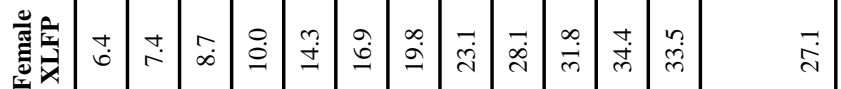

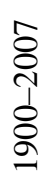

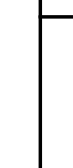
跣

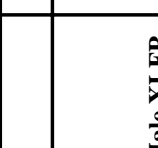

곤 호용

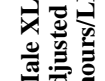

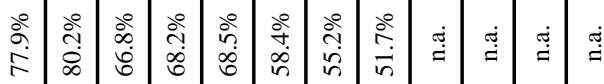

$\frac{\circ}{\circ}$

㐫

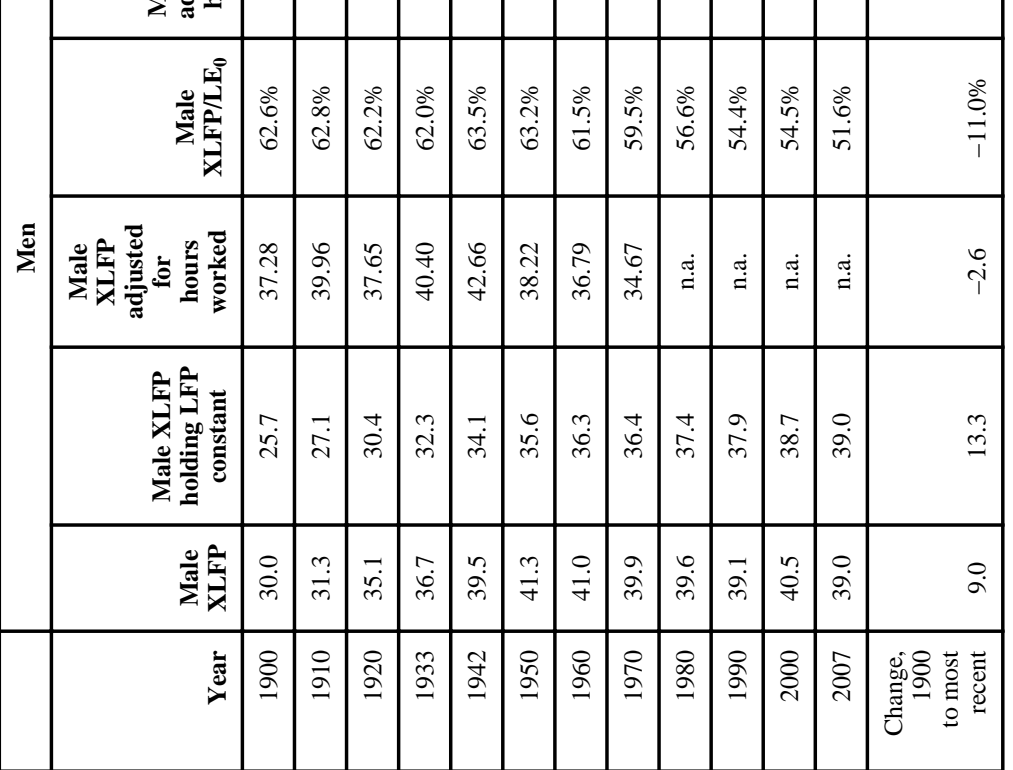

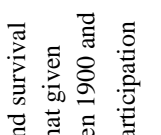

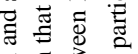

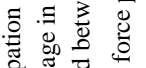

흘

总 焉

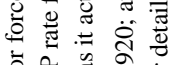

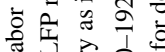

势

记

言焉焉焉

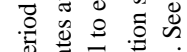

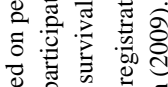

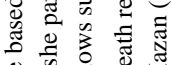

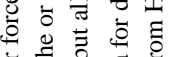

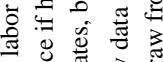

잉

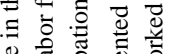

惭

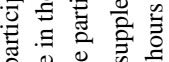

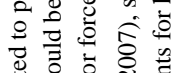

这 类

$\because$ 证

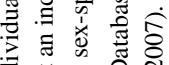

要类

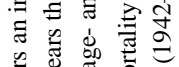

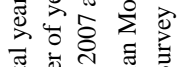

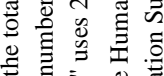

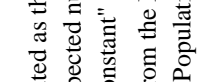

을

$\dot{s}$

I

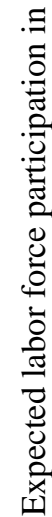

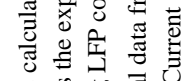

에

座递家

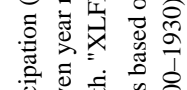

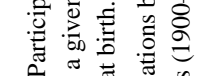

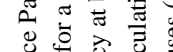

它记

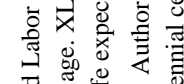

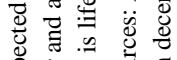

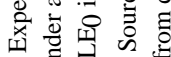

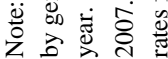


Table 2

The "Longevity Transition" in Asia and Select Developing Countries

\begin{tabular}{ll}
\hline Country & $\begin{array}{l}\text { Change in years lived past 65 as a } \\
\text { percentage of change in life expectancy at } \\
\text { birth, 1990-2010 }\end{array}$ \\
\hline Japan & Males 72.7\%, Females 87.0\% \\
\hline South Korea & Males 45.4\%, Females 57.1\% \\
\hline China & Males 51.9\%, Females 40.6\% \\
\hline Philippines & Males 26.2\%, Females 36.0\% \\
\hline Indonesia & Males 26.1\%, Females 35.7\% \\
\hline Brazil & Males 34.2\%, Females 35.0\% \\
\hline Vietnam & Males 32.5\%, Females 34.7\% \\
\hline India & Males 23.6\%, Females 25.8\% \\
\hline Bangladesh & Males 20.7\%, Females 25.4\% \\
\hline
\end{tabular}

Source: Authors' calculations based on the life tables for each country prepared by the International Programs Center of the U.S. Bureau of the Census in its International Data Base. 